\title{
Editorial
}

\section{Addressing the Model Minority Myth from a Cognitive Perspective}

\author{
Eleazar Cruz Eusebio, PsyD, NCSP* \\ Office of Psychological Services, Prince George's County Public Schools, 8908 Riggs Road, Adelphi, MD 20783, USA \\ *Corresponding author \\ Eleazar Cruz Eusebio, PsyD, NCSP \\ Licensed School Psychologist, Office of Psychological Services, Prince George's County Public Schools, 8908 Riggs Road,Adelphi, MD 20783, USA; \\ E-mail: ecepsyd@gmail.com
}

\section{Article information}

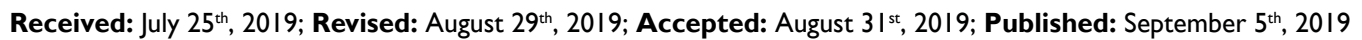

\section{Cite this article}

Eusebio EC.Addressing the model minority myth from a cognitive perspective. Psychol Cogn Sci Open J. 2019; 5(2): el-e3. doi: 10.17।40/PCSOJ-5-e012

$\mathrm{T}$ There has been a lot of emphasis on Asian Pacific Americans as the Model Minority as they are currently the fastest-growing minority demographic in the U.S. The U.S. Asian population grew $72 \%$ between 2000 and 2015 from 11.9 million to 20.4 million, the fastest growth rate of any major racial or ethnic group. This immigration wave from Asia accounts for a fourth of all immigrations to the United States since 1965. ${ }^{1}$ The current Asian Pacific American status perpetuates and characterizes the pervasive and widely inaccurate "model minority myth" which emerged and is accredited to William Petersen in an article he wrote entitled "Success Story, Japanese-American Style" in $1966 .^{2}$ A few months later, a similar article, "Success Story of One Minority Group in the United States" emerged in U.S. News and World Report ${ }^{3}$ portraying the success of Chinese Americans, yet making unparalleled comparisons that maligned African Americans. Both articles successfully demonstrated how Asian cultural values allowed them to succeed against the odds in America by citing statistics on rising educational attainment and income levels coupled with statistics on low rates of reported crime and mental illness. However, the resulting misalignment of ethnic minority groups and unfair treatment of a whole demographic as successful served nothing more than to further marginalize Asian Pacific Americans.

It is critical to look at the credibility of the Model Minority Myth from a cognitive perspective because the cognitive approach in psychology involves human behavior that focuses on how we think which, in turn, affects the way that we behave. After more than a century of invisibility combined with separatist and inexcusable vitriol to the point of eliminating and imprisoning Japanese Americans in internment camps after World War II, the tables briefly turned in the 1970s. Later, the United States made formal apologies and signed legislation in a formal apology which paid out $\$ 20,000$ in compensation to each surviving victim.
However, the radical attitude shift was suspicious for Asian Pacific Americans who had become familiar with the "friend today, foe tomorrow" mentality as they were inadvertently refashioned as a political and social hammer against other disadvantaged groups by the government in the United States. Asian Pacific Americans were faced with the conundrum to accept the model minority status as a major improvement over the mysterious and perpetually alien enemy from the East. ${ }^{4}$ Other ethnic minority groups began to see Asian Pacific Americans as a demographic that was given unwarranted privileges that were not to be trusted.

Although the stereotype initially seemed a positive one, it has perpetuated three inherent negative effects. First, and perhaps the most deleterious, is in the intergroup relations and how the model minority myth pits Asian Pacific Americans against other groups targeted by racism in the United States. The underlying message from the dominant White culture to other ethnic minority groups is "Asians overcame discrimination, so why can't you?" This is both dangerous and damaging to the relations between Asian Pacific Americans and other ethnic minorities. Secondly, uncritical acceptance of the stereotype has detrimentally concealed the issues and needs of the Asians in America who have not come anywhere close to experiencing any of the success the stereotype inherently suggests. Finally, the myth contributes to White resentment which led to an increase in anti-Asian violence, particularly after the post911 era.

The most damaging effects of the model minority myth come from the misinterpretation of statistical research that obscure the actual facts, specifically that Asian Pacific Americans are better educated, on average, then Whites and that they have a higher reported average household income than the average White family. ${ }^{5}$ These misrepresented facts are harmful in that the inac- 
curacies are profoundly irresponsible while not stating the fact that, when compared to equally qualified individuals, Asian Pacific Americans consistently earn less than Whites, despite reports that state they are consistently the top earners in America today. Furthermore, Asian Pacific Americans tend to have more family members contributing to the household income. Income inequality is rising more rapidly among Asian Pacific Americans than any other ethnic groups in America, revealing wide disparities in income among the demographic as a whole.

Speaking about the deleterious effects is critical, but we must also examine what happens to people's subsequent behavior from the cognitive perspective. The cognitive model describes how people's perceptions of, or spontaneous thoughts about, situations influence their emotional, behavioral and subsequent physiological reactions and, therefore, correcting the misinformation that leads to one's thoughts is key. The Model Minority Myth must be dispelled as it continually misleads society's perception of Asian Pacific Americans by excluding the critical elements of the theory, homogenizing an entire demographic, thereby, ignoring the rights and historical underpinnings of the entire demographic.

When the data is accurately disaggregated and properly representative of the 43 countries that constitute Asian Pacific America, varying levels of inequality are clearly identified. For example, 35\% of Laotian Americans, 43\% of Cambodian Americans, and more than $25 \%$ of Vietnamese Americans live in poverty, as compared to $13 \%$ of the general United States population. In addition, educational attainment data reveal wide variations among Asian Pacific Americans. Much of the data reported has often shown the demographic as achieving the highest level of education among all ethnic and racial groups in America. However, despite the overall homogenous success of Asian Pacific Americans, upon closer examination of the statistics, some demographics within the broader culture are in direct contrast to the stereotype. For example, high school completion rates are approximately only $35 \%$ among Cambodian Americans, 36\% for Laotian Americans, and $58 \%$ for Vietnamese Americans. Conversely, high school graduation rates are $82 \%$ for Asian Pacific Americans as a homogenous group. ${ }^{6}$

The model minority myth also deleteriously serves to further isolate and misrepresent students in the Asian Pacific American demographic. Not only is there a pervasive expectation for students to outperform and excel in mathematics and science, they are often encouraged to pursue fields in science, technology, engineering, and mathematics (STEM) despite other academic interests. It was not until more recently that STEM included and integrated the Arts.

The positive stereotype perpetuates that Asian Pacific Americans are quiet and content with their status quo and that any sense of advocacy may appear unexpected and angry. The process of finding oneself as perpetually invisible, silent, and in a subservient and agreeable position to the dominant White culture often puts Asian Pacific Americans in a position of further invisibility, silence, and ultimately, oppression in the United States.
The U.S. government has a history of developing and applying race-based discriminatory and exclusionary policies to a variety of ethnic and racial groups throughout history. Cultural identities are not solely determined by racial ideologies, but racism increases the need for a positive self-defined identity in order to survive psychologically in a multicultural and egalitarian society. In turn, many ethnic minorities adopt a mindset of being inherently oppressed by accepting the concept that they have been marginalized by society. This is not a strengths-based mentality, but rather one that lends itself to a negative self-image.

The impetus behind writing this editorial is to acknowledge and enact change in identifying areas that still desperately need formal investigation and reconstitution in order to dispel a vastly used, but continuously disproved stereotypical myth that, inadvertently or not, perpetuates racist inequities within and outside of the Asian Pacific American demographic. This editorial is, in no way, attempting to reverse the repercussions of the misguided use of the Model Minority Myth, but rather introduce a different perspective of the demographic based on data. The objective is to identify the areas where the myth is misleading, but served its purpose in how the U.S. identified the demographic, in many ways the best way it could. It provided a positive outlook for a widely misunderstood and new demographic of immigrants in America. However, it unintentionally represented anyone who identified as Asian Pacific American as successful with their finances and in education. Although, there is some data that proves this may be true for some, it is a misnomer as it is not true for all. Intercultural relations between varying ethnic minority groups as well as White culture in America are further jeopardized with the inaccuracies and damaging stereotypes of Asian Pacific Americans. Most importantly, children of Asian Pacific American upbringing have been taught to follow and subscribe to the myth, inadvertently perpetuating its stereotypical message. Of course, there are some who may believe that the Model Minority Myth has been beneficial to Asian Pacific Americans because of the elevated financial and social status it portrays anyone in the demographic. But, without disaggregating the data, the blanket concept does not represent every ethnicity within the entire Asian Pacific American demographic. Unless we denounce as an artifact, they will continue to accept and live in a society that does not responsibly correct its misguided information. So, in 2020 and beyond, let's face and dispel the ugly stereotypical factors and move into a more just and equitable world where myths are debunked in exchange for actual, accurate, and responsible data. Cognitive science and the future will thank us for it.

\section{REFERENCES}

1. López G, Ruiz NG, Patten E. Key facts about Asian Americans, a diverse and growing population. Web site. https://www.pewresearch.org/fact-tank/2017/09/08/key-facts-about-asian-americans/. Accessed July 24, 2019.

2. Pettersen W. Success story, Japanese-American style. The New York Times. January 9, 1966: Web site. http://inside.sfuhs.org/ 
dept/history/US_History_reader/Chapter14/modelminority.pdf. Accessed July 24, 2019.

3. U.S. News and World Report. Success story of one minority group in the United States. December 26, 1966: Web site. http:// sites.uci.edu/asianamstoriesf17/files/2017/09/modelmin.pdf. Accessed July 24, 2019.

4. Lee SJ. The model minority and the perpetual foreigner: Stereotypes of Asian Americans. In: Asian American Psychology. Oxford- shire, UK: Psychology Press; 2008: 119-134.

5. Sue DW, Bucceri J, Lin AI, Nadal KL, Torino GC. Racial microaggressions and the Asian American experience. Cultural Diversity and Ethnic Minority Psychology. 2007; 13(1): 72-81. doi: 10.1037/10999809.13.1.72

6. Rumbaut RG. Vietnamese, laotian, and cambodian Americans. In: Asian Americans: Contemporary Trends and Issues. California, USA: Sage Publications; 2006. 